\title{
LONG-TERM RESULTS OF CHARNLEY LOW-FRICTION ARTHROPLASTY IN YOUNG PATIENTS
}

ATUL B. JOSHI, MARTYN L. PORTER, IAN A. TRAIL, LINDA P. HUNT, JOHN C. M. MURPHY, KEVIN HARDINGE

From Wrightington Hospital, Wigan, England

We report the long-term outcome of 218 Charnley lowfriction arthroplasties in 141 patients who were $\mathbf{4 0}$ years old or younger at the time of surgery. The minimum followup was ten years with a mean of 16 years. The probability of the femoral component surviving 20 years was $86 \%$ and of the acetabular component, $84 \%$. The chance that both components would survive for this period was $75 \%$.

The pathological diagnosis significantly influenced implant survival. In rheumatoid patients the probability of both components surviving at 20 years was $96 \%$ compared with $51 \%$ in patients with osteoarthritis. Clinical assessment of 103 patients (166 hips) in whom the arthroplasty was still functioning showed that $94 \%$ of hips had minimal pain or none.

We conclude that in young patients cemented total hip replacement is a good procedure for those with rheumatoid arthritis but that the results are much less reliable in those with osteoarthritis.

J Bone Joint Surg [ Br] 1993; 75-B:616-23.

Received 24 August 1992; Accepted after revision 17 November 1992

The dramatic relief of pain, enhanced mobility and restoration of function afforded by total hip replacement make the procedure attractive to all patients with debilitating hip disease (Eftekhar 1987). In young patients, however, there are concerns about aseptic loosening (Chandler et al 1981; Sharp and Porter 1985; White 1988) and alternative treatment such as osteotomy

A. B. Joshi, MCh Orth, FRCS Ed, Research Fellow

I. A. Trail, FRCS, Consultant Orthopaedic Surgeon

J. C. M. Murphy, FRCS, Consultant Orthopaedic Surgeon

K. Hardinge, MCh Orth, FRCS, Consultant Orthopaedic Surgeon

Centre for Hip Surgery, Wrightington Hospital NHS Trust, Appley Bridge, Wigan, Lancashire WN6 9EP, UK.

M. L. Porter, FRCS Ed, FRCS Ed(Orth), Consultant Orthopaedic Surgeon

Royal Preston Hospital, Sharoe Green Lane North, Fulwood, Preston, Lancashire PR2 4QF, UK.

L. P. Hunt, PhD, Statistician

Computational Group, Faculty of Medicine, Manchester Royal Infirmary, Oxford Road, Manchester M13 9WL, UK.

Correspondence should be sent to Mr K. Hardinge.

(C) 1993 British Editorial Society of Bone and Joint Surgery $0301-620 \mathrm{X} / 93 / 4581 \$ 2.00$
(Poss 1984) or arthrodesis (Sponseller, McBeath and Perpich 1984) has been considered. In our experience, most young patients will press for arthroplasty as the treatment of choice and in order to advise them of the risks involved, clinicians need accurate data on the longterm performance of hip replacement.

We report the results of implant survival in 141 patients who were aged 40 years or less at the time of surgery and who were followed for a mean 16 years.

\section{PATIENTS AND METHODS}

During the period 1966 to 1980 , a total of 11189 hips were operated on under the supervision of Sir John Charnley and the two senior authors (JCMM and KH) at the Centre for Hip Surgery, Wrightington. Of these, $218(1.95 \%)$ were in 141 patients aged 40 years or less at the time of surgery. There were 97 women and 44 men with a mean age at surgery of 32 years (16 to 40$)$. The operation was unilateral in 64 patients and bilateral in 77. There were 115 left and 103 right hip replacements. The hospital's clinical database was searched and an effort was made to contact all these patients. It was known that 24 patients ( 32 hips) had died, and a further 14 ( 20 hips) could not be contacted. With the exception of one patient, the deaths had occurred more than one year after surgery. The records of all the patients who had died or were lost to follow-up were used to establish the duration of their follow-up, whether the hip had been revised and, if so, the reason for the revision.

The remaining 103 patients (166 hips) attended for clinical and radiological assessment in the first quarter of 1990 , a recall rate of $88 \%$ of surviving patients. These patients had a mean follow-up of 16 years (10 to 24).

Kaplan-Meier survival estimates were calculated for all 218 hips (141 patients) (Peto et al 1977). Separate curves were constructed using three criteria as end-points as follows:

All revisions for any reason. Reoperation and removal of the femoral and/or the acetabular component for infection, dislocation or mechanical loosening.

Stem revision. Reoperation for aseptic loosening of the femoral component, either alone or in combination with a loose acetabular component.

Cup revisions. Reoperation for aseptic loosening of the 
acetabular component, either alone or in combination with a loose femoral component.

Risk factors, including age, sex, weight, diagnosis, and previous surgery, were assessed using log-rank tests. Patients were grouped according to age at surgery as follows: 25 years or less, 26 to 30 years, 31 to 35 years, and 36 to 40 years. We also compared patients weighing less than $70 \mathrm{~kg}$ with those weighing $70 \mathrm{~kg}$ or more.

Clinical assessment was by the Merle d'Aubigné and Postel (1954) system. Since some patients, for example those with a pseudarthrosis, have a high score from a good range of passive movement, we also measured the combined range (in degrees) of active straight-leg raising and active abduction.

Charnley (1979) advocated that patients be grouped according to their preoperative disability. Thus, in group A one hip only was affected, in group B two hips were involved and in group $C$ there was other significant disease (e.g. cardiac, neurological) which directly impaired walking. We have not used these categories since we found, in this long-term study, that a patient's rating often deteriorated as the result of contralateral hip pathology or other medical conditions.

Radiological data. Measurements were made directly on the radiographs taken postoperatively, at one year and at final review.

Femoral component. We measured, in each of the zones of Gruen, McNeice and Amstutz (1979), separation of the stem from the cement, fracture of the cement mantle, calcar porosis, calcar rounding, loss of calcar height, stem tilt or pivot, and bone cement demarcation. Subsidence was graded as either none, $5 \mathrm{~mm}$ or less, or more than $5 \mathrm{~mm}$.

Acetabular component. Demarcation was recorded in the zones described by DeLee and Charnley (1976). Loosening was assessed using the criteria of Hodgkinson, Shelley and Wroblewski (1988).

Statistics. The data were analysed by the Faculty of Medicine Computational Group, Victoria University of Manchester using the Lifetest procedure (SAS 1985).

\section{RESULTS}

Forty-one hips were replaced below the age of 25 years; 47 between 26 and 30 years; 68 between 31 and 35 years; and 62 between 36 and 40 years of age.

There were four pathological groups: 74 hips had rheumatoid arthritis (RA), 47 had congenital dysplasia (CDH), 41 had ankylosing spondylitis (AS) and 56 had osteoarthritis (OA). Of the last group, in 11 the OA was primary and in 45 secondary to a variety of primary conditions (trauma 14, avascular necrosis 7, Perthes' disease 6, sepsis 4, and others 14). In the RA group 14 patients had died; in the CDH group, one; in the AS group, six; and in the OA group, three.

Previous operations had been carried out on 36 of the hips. Thirteen had had femoral intertrochanteric osteotomy, three open reduction for CDH and one had been arthrodesed. The remainder had undergone a variety of arthroplasties including replacement with Teflon cups, Smith-Peterson cups and Judet prostheses, and excision arthroplasty.

Complications had developed in 25 hips (11.5\%). There was one perioperative death, in a patient with ankylosing spondylitis who had developed aortic dissection secondary to aortitis. There were three cases of delayed wound healing and three of wound haematoma. Five hips had early wound infection, superficial in four. Two hips developed late haematogenous infection. There were two dislocated hips and six cases of heterotopic ossification. Five trochanters failed to unite.

The retrospective nature of this study precluded us from commenting on the true incidence of deep-vein thrombosis or pulmonary embolism as these diagnoses were made only on clinical grounds. Most patients had been given Plaquenil (hydroxychloroquine) for thromboembolic prophylaxis, but this was not consistent.

Thirty-three hips had had reoperations. Fifteen had been revised for a loose cup, eight for a loose femoral stem, four for loosening of both components and three for infection. One patient required reoperation for dislocation and two for removal of the trochanteric wires. Survival analysis

All revisions. The probability of implant survival at 20 years was $75 \%$ (Fig. 1). Risk factors such as age, weight and previous surgery proved not to be statistically significant. Sex was significant $(p=0.035)$, males $(55 \%)$ faring worse than females ( $85 \%$ ) (Fig. 2). Diagnosis was highly significant ( $p<0.001$ ), patients with RA having the best prognosis and those with OA the worst. In RA patients the probability of survival at 20 years was $96 \%$ compared with $51 \%$ in the OA group (Fig. 3 ).

The differences between diagnostic groups may have been influenced by sex as more females had RA rather than OA. The difference, however, between the four

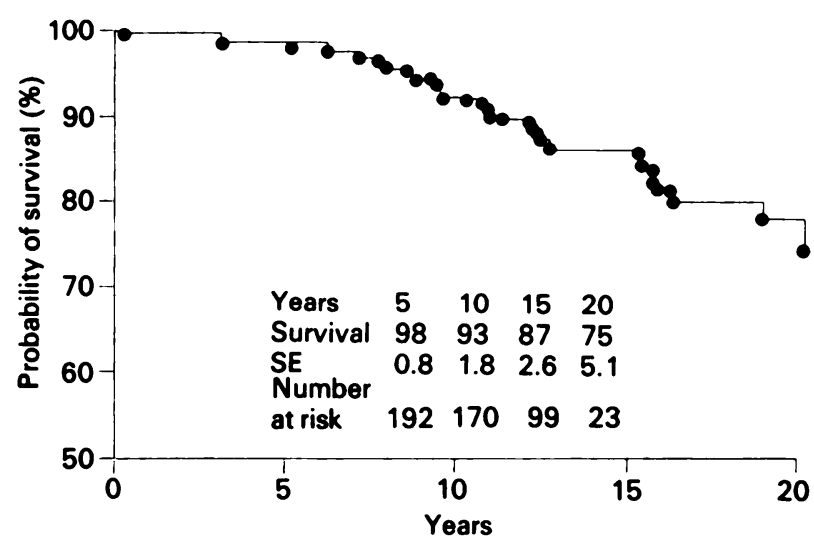

Fig. 1

Survival curve, with failure defined as all revisions for any reason. Inset: percentage survival, standard error and numbers at risk at 5, 10, 15 and 20 years. 


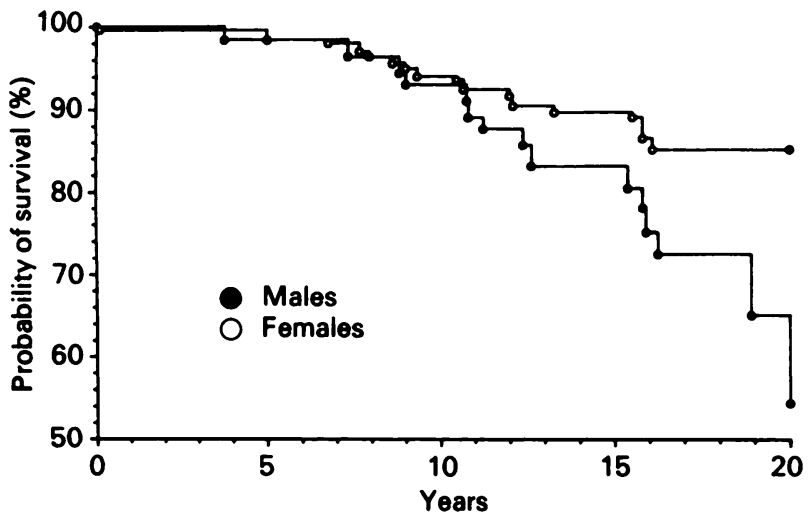

Fig. 2

Survival curves for males and females, with failure defined as revision for any reason.

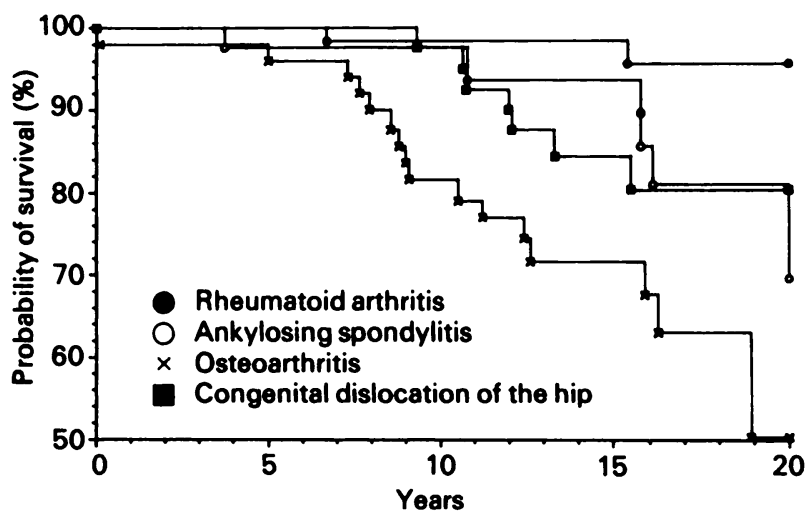

Fig. 3

Survival curves for four primary diagnoses, with failure defined as revision for any reason.

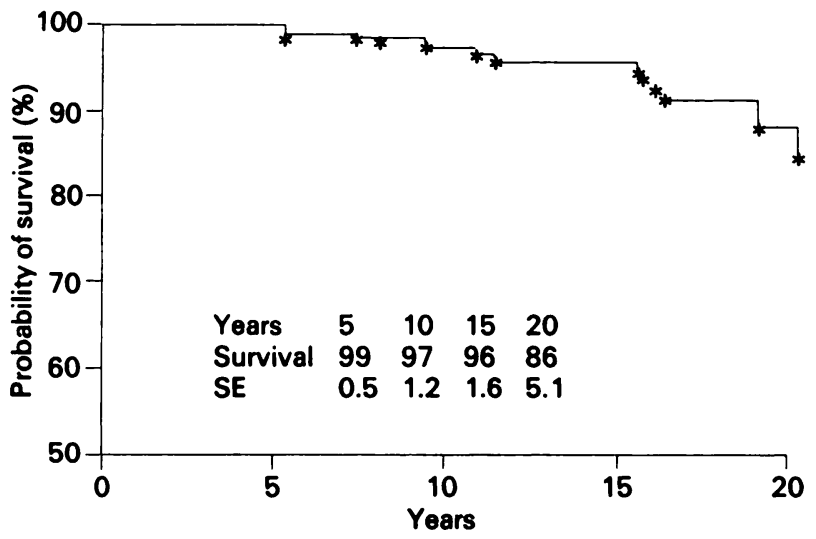

Fig. 4

Survival curve, with failure defined as revision for a loose femoral component. Inset: percentage survival and standard error at 5, 10, 15 and 20 years.

diagnostic groups was still significant after adjustment for sex ( $p<0.005$; Pocock 1983).

Stem revisions. The probability of survival of the femoral component at 20 years was $86 \%$ (Fig. 4). Age, weight and

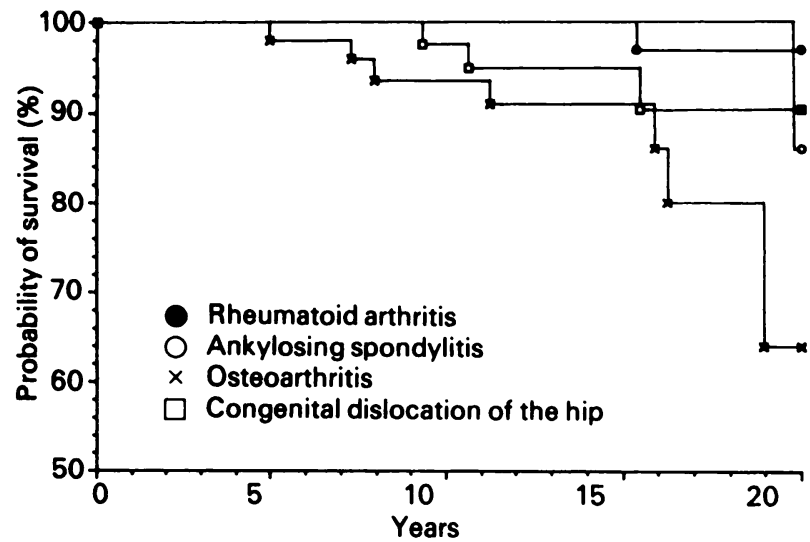

Fig. 5

Survival curves for four primary diagnoses, with failure defined as revision for a loose femoral component.

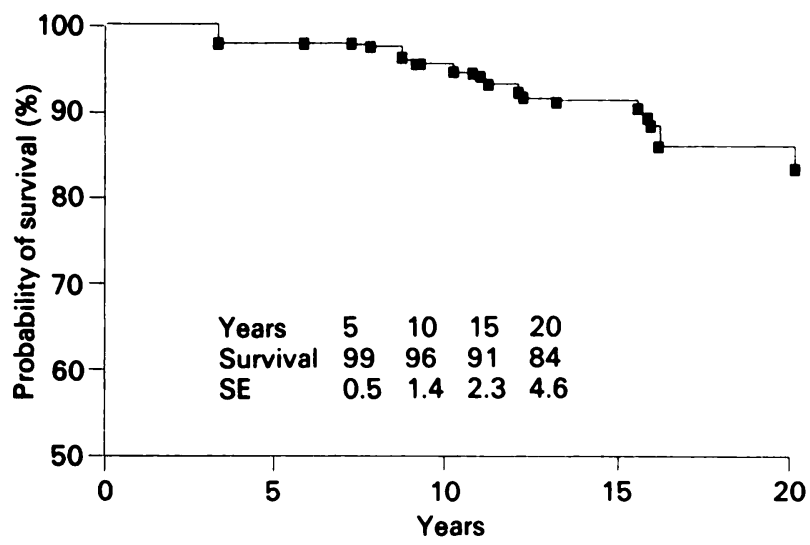

Fig. 6

Survival curve, with failure defined as revision for a loose acetabular cup. Inset: percentage survival and standard error at $5,10,15$ and 20 years.

previous surgery were not significant. For males the probability of survival at 20 years was $65 \%$ and for females $95 \%(p=0.039)$. Diagnosis was a highly significant factor, and followed the pattern for all revisions $(p=0.005$; Fig. 5). Again the differences were still significant after adjustment for sex $(p<0.025$; Pocock 1983).

Cup revisions. The overall probability of survival of the cup was $84 \%$ at 20 years (Fig. 6). Age, sex and weight were not significant. Diagnosis was highly significant $(p=0.038) ; 99 \%$ of rheumatoid patients had a secure cup at 20 years compared with $70 \%$ of those with ankylosing spondylitis (Fig. 7). The probability of cup revision was $28 \%$ in patients who had had previous surgery and $13 \%$ in those who had not which was highly significant $(p=0.004)$. Acetabular components which showed two or more areas of zonal demarcation at one year were significantly more likely to loosen than those which did not $(\mathrm{p}<0.001 ;$ Fig. 8).

Clinical assessment. We examined 103 patients (166 hips) clinically and radiologically representing $88 \%$ of the 


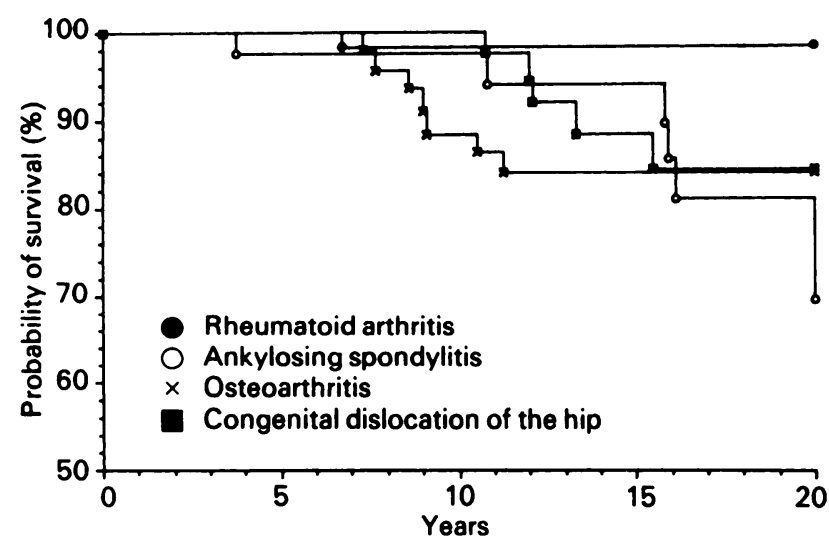

Fig. 7

Survival curves for four primary diagnoses, with failure defined as revision for a loose acetabular cup.

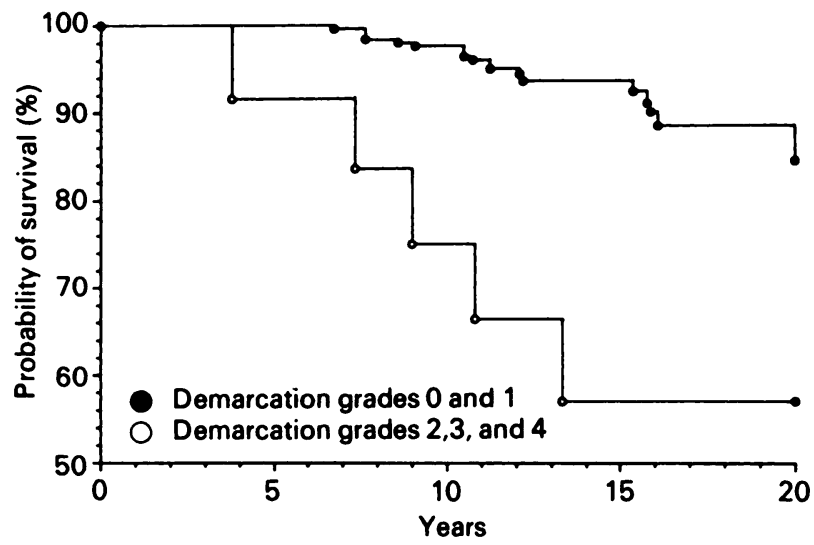

Fig. 8

Survival curves for hips with and without severe demarcation around the acetabulum at one year. Failure was defined as revision for loose cup.

surviving patients. This group did not differ significantly from the original group of patients. Comparisons of their preoperative and postoperative status are shown in Figure 9. The 11 hips which had been painfree before operation were in patients with ankylosing spondylitis and the indication for surgery was ankylosis not pain.

The two patients who had had an excellent range of movement preoperatively both had old CDH and were in severe pain. At review, $94 \%$ of all the hips had little or no pain (grade 5 or 6 ) and $74 \%$ had a combined abduction and flexion range greater than $60^{\circ}$ compared with $19 \%$ preoperatively.

\section{Radiological assessment}

Femur. The femoral component had subsided $2 \mathrm{~mm}$ or less in 132 hips $(79.5 \%$; Fig. 10). In $16.5 \%$ there was subsidence of between 2 and $5 \mathrm{~mm}$ and in $4 \%$ it was more than $5 \mathrm{~mm}$. There were two cement tip fractures at one year and five (3\%) at final follow-up (Fig. 11).

Separation of the femoral component from the cement by more than $2 \mathrm{~mm}$ was not seen at one year but was visible in four hips at review. The cement-bone interface remained perfect in 145 hips (87.3\%; Fig. 10).
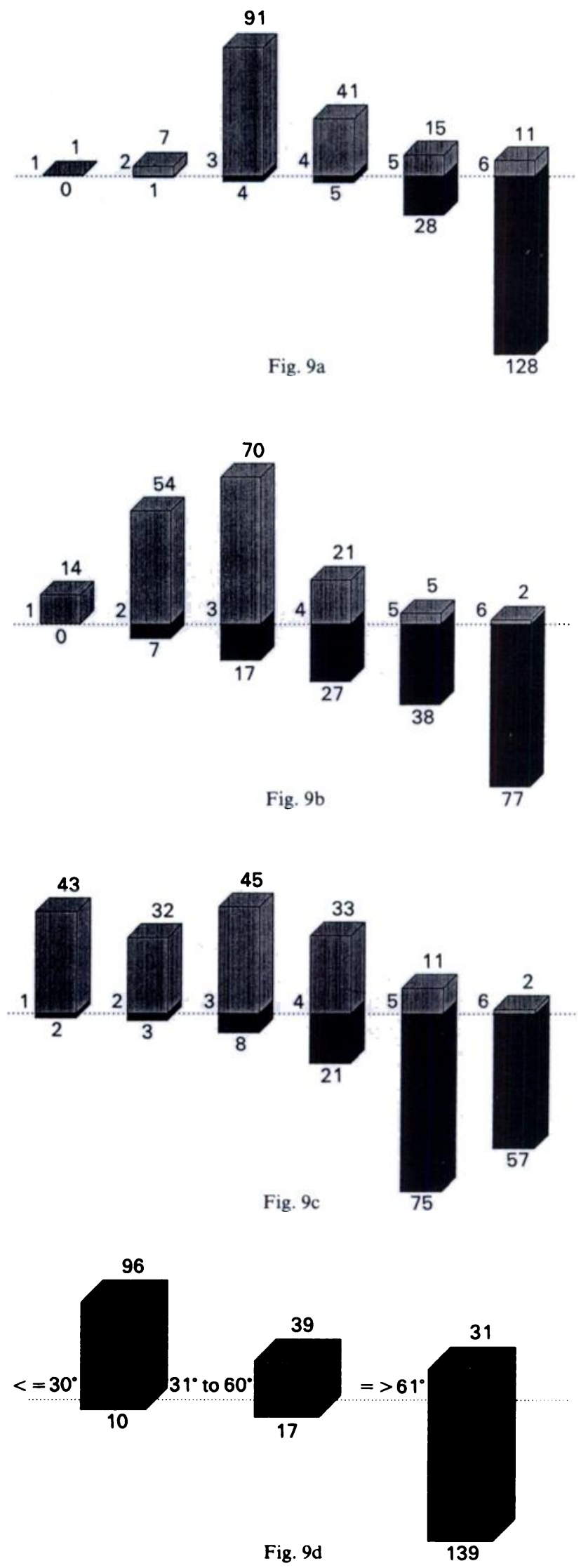

Bar graphs of clinical measures preoperatively (above the line) and postoperatively (below the line) for (a) pain, graded 1 to 6 (b) function, graded 1 to 6 (c) movement, graded 1 to 6 (Merle D'Aubigné and Postel 1954) and (d) movement by degrees of combined active abduction and flexion (see text). 
Fig. 10

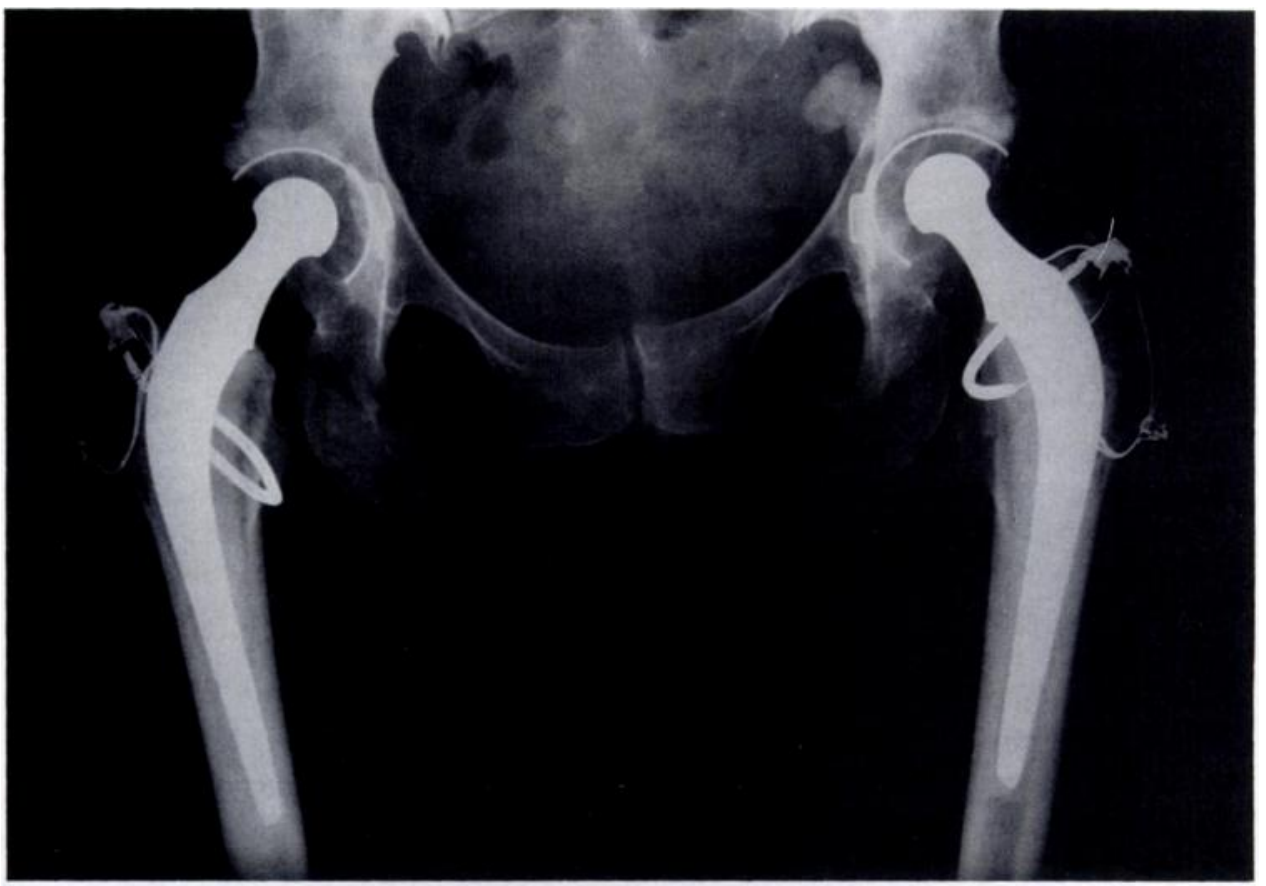

Bilateral THR 16 years after implantation into a 34-year-old woman with acetabular dysplasia. There is appreciable wear of both acetabular cups but no sign of demarcation or subsidence of the implants.

Six hips had demarcation in Gruen zones 3, 4 and 5. The remaining 13 hips showed a scattered zonal distribution of demarcation.

At one year two hips showed rounding off of the cut end of the femoral calcar and 16 calcars were porotic. At review 14 were rounded off and 26 were porotic. Loss of calcar height of more than $5 \mathrm{~mm}$ had occurred in 15 hips at review (Fig. 12).

Thickening of the femoral cortex was seen in 36 hips $(21.6 \%)$ at review; in half the cases zone 3 was involved (Fig. 12). Endosteal cavitation had occurred in 16 hips $(9.6 \%)$ with no specific pattern of zonal involvement.

Acetabulum. Generally, the cement-bone interface remained excellent (Fig. 10). We modified Hodgkinson's (1988) classification as follows: grade 0, no demarcation; grade 1, demarcation in any one zone; grade 2, demarcation in any two zones; grade 3, demarcation in all zones; and grade 4, complete demarcation and cup migration. At one year two cups were completely demarcated and one had migrated. At final follow-up six cups were fully demarcated and seven had migrated (Fig. 11).

Wear measurements made from the radiographs suffered from considerable interobserver error and we were unable to quantify the data. It is intended to use a new image analysis technique (Hardinge et al 1991) to overcome this problem.

\section{DISCUSSION}

High revision rates for aseptic loosening of cemented prostheses have been reported in patients less than 40

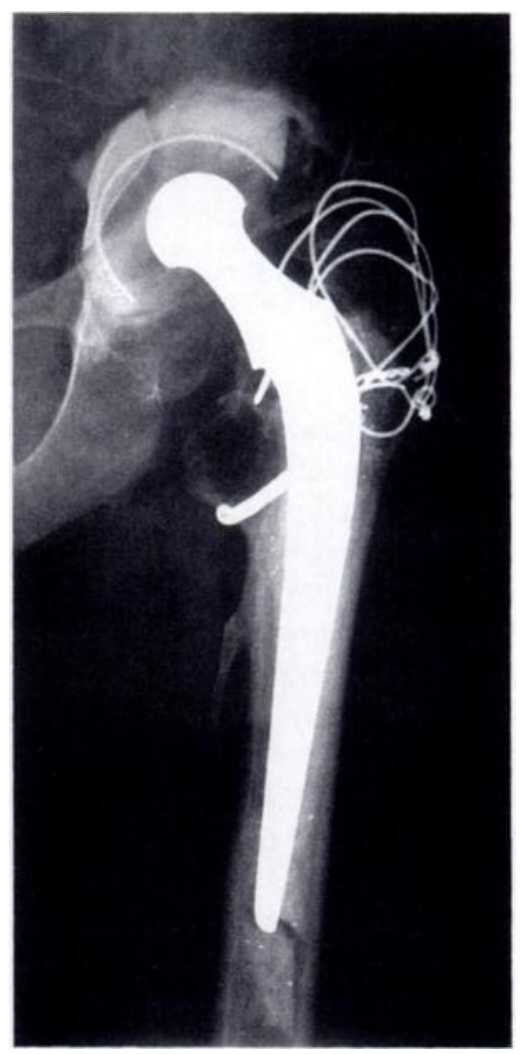

Fig. 11

Left THR 14 years after implantation into a 31-year-old woman with rheumatoid arthritis. The acetabular cup shows migration medially and superiorly and there is fragmentation of the cement mantle in the medulla of the femur. 


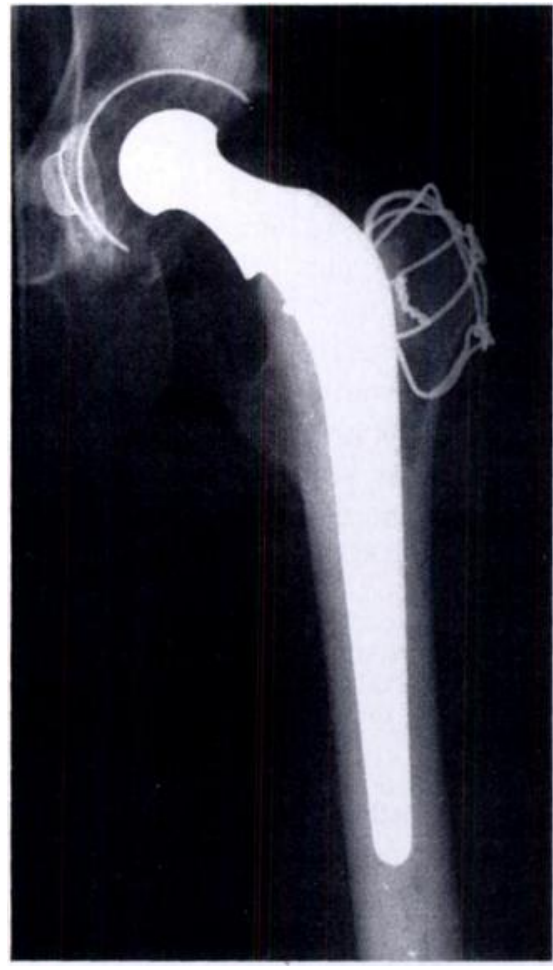

Fig. 12a

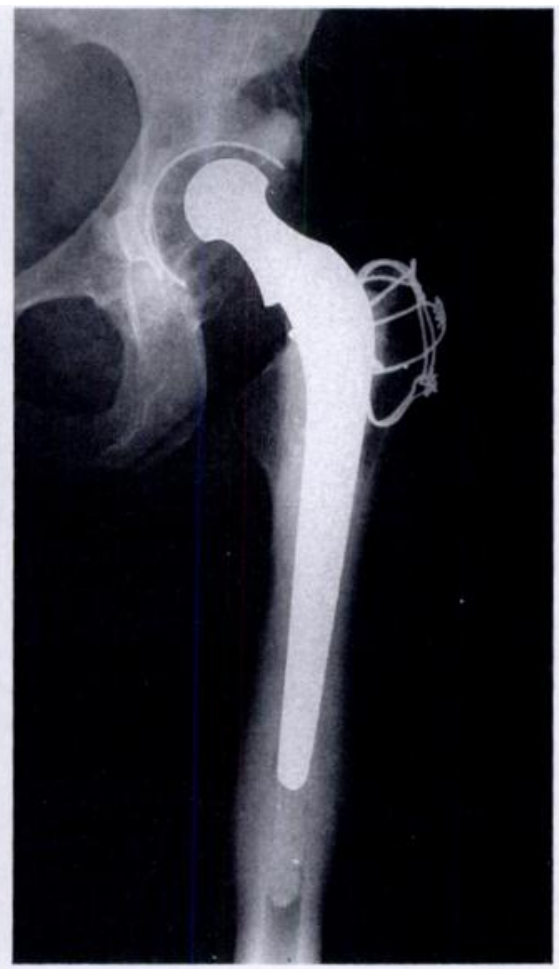

Fig. $12 b$
Left THR performed on a 38-year-old woman with severe acetabular dysplasia. Figure $12 \mathrm{a}-$ Postoperatively, there is a wedge of cement above and lateral to the acetabular cup in zone 1 of DeLee and Charnley (1976). Figure 12bAfter 13 years there is severe wear of the cup and a lytic area above the wedge of cement. There is physiological hypertrophy of the shaft of the femur at the tip of the stem. years of age at the time of surgery (Chandler et al 1981; Gustilo and Burnham 1982; Sharp and Porter 1985; White 1988) and uncemented implants have been used in an attempt to avoid this complication (Engh, Bobyn and Glassman 1987; Jones and Hungerford 1987).

In early studies Halley (1975), Bisla, Inglis and Ranawat (1976) and Colville and Raunio (1979) reported low revision rates for patients followed up for less than five years, but it soon became evident that after five years many more implants failed, although this experience was not uniform. Lachiewicz et al (1986), for example, reported a $3 \%$ revision rate at a mean follow-up of six years while Chandler et al (1981) had a revision rate of $21 \%$ in a comparable study.

It is perhaps of limited value to make detailed comparisons between different series. Each must have had a different mixture of variables relating to patient selection, surgical technique, implant usage, and techniques of analysis.

In recent years there has been a trend towards the use of survival analysis despite its limitations (Johnsson, Thorngren and Persson 1988; Ritter and Campbell 1989). The survival analysis of our series shows that the risk of revision for infection, dislocation and aseptic loosening was $6 \%$ at 10 years and increased to $25 \%$ at 20 years.

When aseptic loosening alone was considered, $3 \%$ of the femoral components were at risk at 10 years and $14 \%$ at 20 years $; 4.5 \%$ of the acetabular components were at risk at 10 years and $16 \%$ at 20 years.

This increase in the risk between 10 and 20 years emphasises the importance of a long-term follow-up
(Eftekhar 1987). Bearing in mind the age of the patients, however, these figures for revision are low (Chandler et al 1981).

Within this highly selected group of patients, all aged $\mathbf{4 0}$ years or less at the time of surgery, age was not a significant risk factor. We think that the pathological diagnosis and the activity level are so intimately related that the effect of chronological age was masked.

Patients with rheumatoid arthritis had a much better prognosis than those with osteoarthritis. The probability of revision of the femoral component at 20 years was $3 \%$, $10 \%$ and $14 \%$ for patients with RA, CDH and AS respectively compared with a revision risk of $36 \%$ for those with OA. Only $2 \%$ of the rheumatoid patients were at risk of revision at 20 years, while the risk in the other groups was between $15 \%$ and $31 \%$. These figures certainly support the continued use of cemented THR in young patients with rheumatoid arthritis.

The performance of the cemented femoral components was also excellent in patients with AS and good in patients with CDH. Again, its continued use is supported.

Of greater concern is the fixation of the acetabular component in patients with $\mathrm{CDH}$ and $\mathrm{AS}$ although the acetabular revision risks at 10 and even 15 years were still acceptably low.

The patients who did least well were those with OA. The risks of revision of both the femoral and acetabular components were high, a combined risk of $20 \%$ at 10 years and nearly $49 \%$ at 20 years.

At a mean follow-up of 16 years, $94 \%$ of implants which had not been revised were virtually painfree; $68 \%$ 
had excellent or very good function; and $78 \%$ had a full, or almost full range of movement. No patients had pain at rest or severe pain which limited activity.

The radiological assessment of THR is the subject of debate. Brand, Pedersen and Yoder (1986) showed that the incidence of radiological component loosening can vary by a factor of two depending upon definition. Change in position is usually considered to be evidence of implant loosening (Harris, McCarthy and O'Neil 1982) but measurement errors have rarely been addressed. Not everyone accepts that subsidence of the femoral component is a poor prognostic factor (Loudon and Older 1989).

In our study $9 \%$ of stems showed evidence of subsidence at one year compared with $20 \%$ at review. According to the criteria of Harris et al (1982), these stems were definitely loose. If, however, we consider only stem subsidence of more than $5 \mathrm{~mm}$ as evidence of loosening, then the loosening rate was only $0.5 \%$ at one year and $4 \%$ at review.

Hodgkinson et al (1988) established that sockets showing no demarcation were securely fixed, but $7 \%$ of those with demarcation at the outer one-third were loose as were $71 \%$ of those with demarcation of two-thirds. They found at revision that $94 \%$ of sockets with complete demarcation and all which had migrated were loose. In our series cup demarcation at one year was a highly significant prognostic factor for subsequent loosening $(p<0.001)$. If one zone or less was demarcated the revision risk at 20 years was $16 \%$ and if two or more zones of demarcation were present the risk was $43 \%$.

Long-term follow-up is necessary to reveal true failure rates. During this time, developments in surgical technique and implant design will inevitably occur and there is strong circumstantial evidence that modern surgical techniques and implant design will improve implant survival (Harris and White 1982; Burke, Gates and Harris 1984; Russotti, Coventry and Stauffer 1988; Harris and Maloney 1989).

It is at the acetabulum that there have been the most numerous changes. In the 1960 s Charnley advocated medialisation of the cup to maximise the moment arm of the abductors (Charnley 1961). In the 1970s there was a move away from cup medialisation to allow preservation of the subchondral plate, but at the same time a flanged socket was introduced to enhance cement pressurisation.

Over the last eight years more sophisticated methods of cement pressurisation have been used (Fowler et al 1988) and these techniques may show better long-term results.

Another important variable is patient selection. Many of the patients in this series were selected using the 'pseudarthrosis test' (Charnley 1979), the essence of which was to perform THR only if the function and pain grade indicated that a pseudarthrosis would improve the patient's status. The rationale was that even if the prosthesis failed and had to be removed the patient would still be better off. Although the patients in this series were all young, they were all severely disabled and may not be comparable with a series of similarly aged patients chosen for THR today.

The basic design principles of the Charnley THR are once again validated by a long-term clinical, radiological study. These principles include a femoral head of small diameter $(22.25 \mathrm{~mm})$ with a tapered stem to allow subsidence within the cement mantle and a ratio between the internal and external radii of the cup such that the torque at its cement-bone interface is reduced. The study has shown that in young patients having cemented hip replacement there is a greater risk of revision for those with osteoarthritis than for those with rheumatoid arthritis.

We wish to acknowledge the secretarial help of Ellen Jenkins and Beverly Haerris in the preparation of this paper. This work was supported by the Arthritis Research Trust, Wrightington Hospital.

No benefits in any form have been received or will be received from a commercial party related directly or indirectly to the subject of this article.

\section{REFERENCES}

Bisla RS, Inglis AE, Ranawat CS. Joint replacement surgery in patients under thirty. J Bone Joint Surg [ Am] 1976; 58-A :1098-104.

Brand RA, Pedersen DR, Yoder SA. How definition of "loosening" affects the incidence of loose total hip reconstructions. Clin Orthop $1986 ; 210$ :185-91.

Burke DW, Gates EI, Harris WH. Centrifugation as a method of improving tensile and fatigue properties of acrylic bone cement. $J$ Bone Joint Surg [Am] 1984; 66-A:1265-73.

Chandler HP, Reineck FT, Wixson RL, McCarthy JC. Total hip replacement in patients younger than thirty years old: a five-year follow-up study. J Bone Joint Surg [ Am] 1981; 63-A :1426-34.

Charnley J. Arthroplasty of the hip: a new operation. Lancet 1961; i:1129-32.

Charnley J. Low friction arthroplasty of the hip: theory and practice. Berlin, etc: Springer-Verlag, 1979.

Colville J, Raunio P. Total hip replacement in juvenile rheumatoid arthritis. Acta Orthop Scand 1979; 50:197-203.

DeLee JG, Charnley J. Radiological demarcation of cemented sockets in total hip replacement. Clin Orthop 1976; $121: 20-32$.

Eftekhar NS. Long-term results of cemented total hip arthroplasty. Clin Orthop 1987; 225:207-17.

Engh CA, Bobyn JD, Glassman AH. Porous-coated hip replacement: the factors governing bone ingrowth, stress shielding, and clinical results. J Bone Joint Surg [Br] 1987; 69-B:45-55.

Fowler JL, Gie GA, Lee AJC, Ling RSM. Experience with the Exeter total hip replacement since 1970. Orthop Clin North Am 1988; 19:477-89.

Gruen TA, McNeice GM, Amstutz HC. "Modes of failure" of cemented stem-type femoral components: a radiographic analysis of loosening. Clin Orthop 1979; $141: 17-27$.

Gustilo RB, Burnham WH. Long-term results of total hip arthroplasty in young patients. In: Nelson JP, ed. The Hip. Proc 10th meeting of the Hip Society. St Louis, etc: CV Mosby Co, 1982:27-33.

Halley DK, Charnley J. Results of low friction arthroplasty in patients thirty years of age or younger. Clin Orthop 1975; 112:180-91.

Hardinge K, Porter ML, Jones PR, Hukins DWL, Taylor CJ. Measurement of total hip prostheses using image analysis: the MAXIMA hip technique. J Bone Joint Surg [Br] 1991; 73-B: 724-8.

Harris WH, Maloney WJ. Hybrid total hip arthroplasty. Clin Orthop $1989 ; 249: 21-9$. 
Harris WH, McCarthy JC Jr, O'Neill DA. Femoral component loosening using contemporary techniques of femoral cement fixation. J Bone Joint Surg [Am] 1982; 64-A :1063-7.

Harris WH, White RE Jr. Socket fixation using a metal-backed acetabular component for total hip replacement: a minimum fiveyear follow-up. J Bone Joint Surg [ Am] 1982; 64-A :745-8.

Hodgkinson JP, Shelley P, Wroblewski BM. The correlation between the roentgenographic appearance and operative findings at the bone-cement junction of the socket in Charnley low friction arthroplasty. Clin Orthop 1988; 228:105-9.

Johnsson R, Thorngren K-G, Persson BM. Revision of total hip replacement for primary osteoarthritis. J Bone Joint Surg [Br] $1988 ; 70-B: 56-62$

Jones LC, Hungerford DS. Cement disease. Clin Orthop 1987; 225 :192206.

Lachiewicz PF, McCaskill B, Inglis A, Ranawat CS, Rosenstein BD. Total hip arthroplasty in juvenile rheumatoid arthritis: two to eleven-year results. J Bone Joint Surg [ Am] 1986; 68-A:502-8.

Loudon JR, Older MWJ. Subsidence of the femoral component related to long-term outcome of hip replacement. J Bone Joint Surg [Br] $1989 ; 71-B: 624-8$

Merle d'Aubigné R, Postel M. Functional results of hip arthroplasty with acrylic prosthesis. J Bone Joint Surg [Am] 1954; 36-A: $451-75$
Peto R, Pike MC, Armitage P, et al. Design and analysis of randomized clinical trials, requiring prolonged observation of each patient: II, analysis and examples. Br J Cancer 1977; 35:1-39.

Pocock SJ. Clinical trials: a practical approach. John Wiley \& Sons, Chichester, 1983

Poss R. Current concepts review. The role of osteotomy in the treatment of osteoarthritis of the hip. J Bone Joint Surg [Am] 1984; 66A :144-51.

Ritter MA, Campbell ED. The survival of the cemented femoral component of a total hip replacement. Clin Orthop 1989; 243: 143-7.

Russotti GM, Coventry MB, Stauffer RN. Cemented total hip arthroplasty with contemporary techniques: a five-year minimum follow-up study. Clin Orthop 1988; 235:141-7.

SAS user's guide: Basics: Version 5 edition. Cary, North Carolina : SAS Institute Inc: $1985: 213$.

Sharp DJ, Porter KM. The Charnley total hip arthroplasty in patients under age 40. Clin Orthop 1985; $201: 51-6$.

Sponseller PD, McBeath AA, Perpich M. Hip arthrodesis in young patients: a long-term follow-up study. J Bone Joint Surg [Am] 1984 ; 66-A :853-9.

White SH. The fate of cemented total hip arthroplasty in young patients. Clin Orthop 1988; $231: 29-34$ 